\title{
Application of IQA Method to Discuss Augmented Reality Learner's Mind Map
}

\author{
Kao Hsuan Jan \\ The Graduate Institute of Design Science, Tatung University, Taiwan \\ Email: hsuanjan@gmail.com
}

How to cite this paper: Jan, K. H. (2018) Application of IQA Method to Discuss Augmented Reality Learner's Mind Map. Psychology, 9, 2103-2115.

https://doi.org/10.4236/psych.2018.98120

Received: May 28, 2018

Accepted: August 10, 2018

Published: August 13, 2018

Copyright (C) 2018 by author and Scientific Research Publishing Inc. This work is licensed under the Creative Commons Attribution International License (CC BY 4.0).

http://creativecommons.org/licenses/by/4.0/

\begin{abstract}
The study has discussed the thought of inner mind of Augmented Reality learners by interactive qualitative research methods. The participants were juniors and seniors in college who have set a special topic in Augmented Reality Design. The study found that: 1) The concept of the learning mind presented by Augmented Reality learner is consistent with the main driver project and the output concept of the main outcome. It is obvious that the plan and result of Augmented Reality learning are the main conceptual factor.

2) The junior learners present linear mental thoughts during the learning process and have accumulated the required knowledge concept skills step by step. 3) The senior learners have accumulated a certain amount of learning experience, and thus they present an interactive cycling mental model of learning. 4) The logical editing ability of animation technique and interactive design plays an important interactive factor in the learner's Mental Model. Logical editing ensures student's ideas are accessible and fun to design. It also explains the learner's psychological thoughts through a mental model and guides learner's perception and behavior to solve problems.
\end{abstract}

\section{Keywords}

Augmented Reality, Interactive Design, Logical Editing, Mental Model

\section{Introduction}

\section{Background and Motivation}

Digital media design has a shorter history in education of design, but the knowledge field it has involved is vast. Various fields can be applied in digital media design. The convenience, interest, usability, and education that it has brought have deeply affected modern society of information. Digital media design can be 
seen everywhere. If we can further integrate the concept of service design sustainability, while confronting with a society with higher changed information, "Sustainable Development" in 21 st century has obviously become an important issue for all walks of life (He \& Song, 2014). Traditional design education or even general education has a very complete and rigorous method of teaching and education. Students who have been cultivated have a certain level of knowledge in design and can make design works or products required by company's employer or general customers according to general work modes in design. However, "Design" still requires "Creativity". Design with no creativity will eventually become a general product. Assuming that the design quality is good and can be accepted by the public, it can maintain a certain value, and such students often study quite hard, and even have a certain talent in design.

Learning related to digital media design is so extensive and complicated that students often feel clueless in their learning and do not know where to start. Therefore, the study has discussed the thinking mode of learner's mind mainly by digital media design of digital content of Augmented Reality digital media design of digital content. With such creative kind of interactive design of Augmented Reality to discuss, think, and amend education in digital media design, the application of integration concept by multimedia through cloud communication of the Internet, the interactivity and immediacy can be promoted. In this way, it allows students to quickly grasp the know-how of digital media design, and also can strengthen the students' receiving mode of single message in the classroom so that they can study and operate more abundantly with interactive ways. Studying and discussing by such Mental Model, we will improve the traditional teaching mode and make digital media design education more comprehensive.

\section{Literature Reviews}

\subsection{Augmented Reality Discussion}

Augmented reality (AR), so-called augmented reality or extended reality is a technique that extends from the field of Virtual Reality (VR). Through Virtual Reality device, virtual objects and scenes are projected in the real world at the same time to create a feeling of being in the environment. Operators can conveniently obtain relevant and useful information about the real world around them when they need it (Chen, 2008).

The initial application of Augmented Reality is a theory that integrates computer vision and real-time calculus into practical applications. In the earlier practices, computer-identifiable symbols, barcodes, or special texts to trigger a series of interactions are required. Using a general webcam device to provide computer vision data, a series of complex media data can then be integrated in a real life.

The current application of AR technology in real life covers many aspects: virtual navigation, interior design, industrial design, medical systems, and inter- 
active interface research, etc. The development of new technologies such as AR, $\mathrm{VR}$, and mixed reality interactive devices is quite advanced and has affected all designs and media industries. These technologies are also refined with the ever-changing smart mobile devices, the processor's computing capability, memory, and increasing storage space. With the increasingly high resolution and quality of displays and video making systems, the integration of AR technology is bound to become a trend and more interactive media applications can then be developed.

\subsection{Multimedia Creative Teaching Discussion}

Through multimedia, a variety of creative ideas can be presented. Therefore, multimedia teaching is very important in creativity training. The development of multimedia technology is fast and convenient, and various kinds of cool and interesting effects can be achieved. In gorgeous multimedia appearance, how to innovate multimedia content has then become the core value required in multimedia teaching.

The initial central target establishment of any design project plan needs to be confirmed rigorously the most. Creative and innovative program content shall affect the development of the overall design. Creativity: to propose new ideas different from those in the past to overcome the problems or challenges it has faced and also creates value. Innovation: practice new ideas, achieve the expectations, goals it has set and create value. From the above-mentioned definitions which are commonly used in the international community, multimedia technology allows creative ideas to have a bigger space for imagination. Based on three aspects of professional competence, creative skills, and internal working motivation (Lien, 2010), it can establish the professional basis of multimedia teaching. The application of multimedia teaching has made it be equipped with more rigorous and perfect planning as well made the core value of teaching more diversified and more flexible.

The design learning reflected in Augmented Reality also comes from the need to solve or improve current situation. It is a design method that takes the user's needs as core value, from observing user's behaviors to discovering user's needs and to test user's preferences, it discusses the relationship between products, services and people, the relationship among people, the relationship between people and the environment, and the relationship between products and the environment on the basis of human (YaHsun, 2013). Similarly, it can be proved that in the case of a multimedia project like digital content of Augments Reality, the learning aspect it needs to be considered is more diversified and rich, and also requires diversified understanding to learn and discuss.

The study has adopted Interactive Qualitative Analysis (IQA) method to collect and analyze data. Through focusing on group interviews and brainstorming, it has gained the concept and ideas of junior students in college when they learn Augmented Reality courses. With the analysis process of diversified data collec- 
tion and systematization, the study organizes learner's mind map (Northcutt \& McCoy, 2004). Then, it crosses and compares by in-depth interviewing with seniors, and analyzes the learner's ideas and experiences through the mind map so as to discuss the development of digital media design teaching. Mind Map is an activity combined both logic and creativity. It allows the brain to solve problems and make decisions in a richer way (Chris Griffiths, 2013). It is a more efficient way of education to learn about learners through Mind Map and also let educators to consider (James Clear Website).

\section{Study Methods}

\subsection{Study Design}

In the first stage, brainstorming was conducted by focus group method, affinity was generated after releasing coding, inducting coding, and spindling coding; and then, in the theoretical coding, it implemented one-on-one affinity comparison, established affinity relationship table (ART), and generates interact relationship drawing (IRD) and found out the determinant, and eventually completes the mind map (SID) of the focus group learners.

In the second stage, it found another group of learners and conducted personal in-depth interviews and oral analysis according to the affinity and sub-affinity generated by the focus group. Then the same theoretical coding was implementd to complete the interviewer's ART, IRD, determinants, and visualized Mind Map. The main purpose of this stage of work was to collect a more comprehensive and comprehensive explanation of each of the affinities as a verification and interpretation of the affinities (shown in Figure 1).

\subsection{Participants Selection}

The focus group method suggested that 6 - 10 people are involved. Too much or too little will lead to efficiency problems (ZiKmund, Cooper, \& Schindler, 2010).

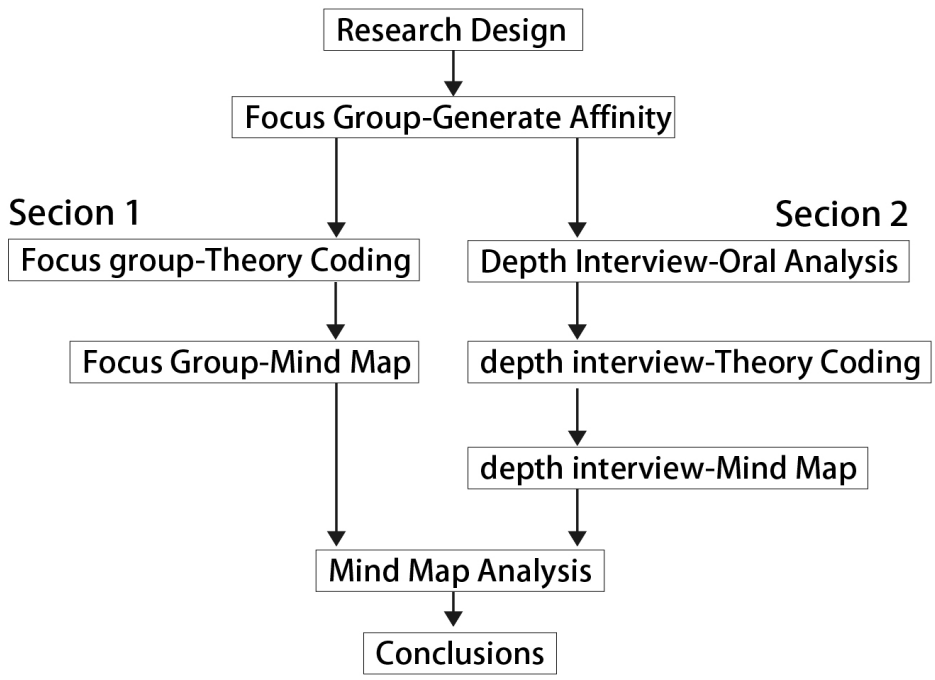

Figure 1. Research flowchart, Source: this study. 
The selection of Augmented Reality learning participants mainly came from Digital Media Design Department students. The conditions were set for students who had taken Interactive Virtual Design courses. The first-stage focus group was 6 participants of juniors, and interviewing of the second-stage consisted of 3 seniors who also studied graduate design courses. The basic student information is shown as Table 1.

\section{Results and Discussion}

\subsection{Focus Group Data Analysis}

\subsubsection{Induction Coding and Spindle Coding}

In the focus group, the questions for 6 junior learners were: "From the experience of making and studying with Augmented Reality, what technical and knowledge concepts do you think should be equipped in the related digital content of Augment Reality?" After completing the ideas of 108 cards, 22 classifications were obtained through the first induction coding, and after the second spindle coding, the affinity of 9 users was generated and summarized in Table 2.

\subsubsection{Theoretical Coding}

1) Affinity relational table analysis

In ART table collected from 6 learners, there were 153 results out of 72 kinds of interactive relationship. Based on the Pareto principle, 153 results were descended in order according to learner's agreement, and the cumulative agreement, cumulative percentage relationship, cumulative percentage agreement, and explanatory power were calculated sequentially. 72 relationships were compiled into Table 3.

2) Pareto and Explanatory Power Analysis

According to the principle of MinMax: the principle of expressing the largest number of variances with the minimum amount of affinity determines which affinity interactive relationship needs to be included in the IRD. The results are shown in 24th relationship (Project Plan $\rightarrow$ Art Style), the explanatory power has

Table 1. Basic information for augmented reality learners.

\begin{tabular}{cclc}
\hline No. & Gender & Grades & Course \\
\hline S1 & male & Junior & Interactive Media Design \\
S2 & female & Junior & Interactive Media Design \\
S3 & male & Junior & Interactive Media Design \\
S4 & male & Junior & Interactive Media Design \\
S5 & female & Junior & Interactive Media Design \\
S6 & female & Junior & Interactive Media Design \\
I1 & male & Senior & Interactive Media Design, Project Design \\
I2 & male & Senior & Interactive Media Design, Project Design \\
I3 & female & Senior & Interactive Media Design, Project Design \\
\hline
\end{tabular}

S1-S6: Juniors, I1-I3: Seniors. 
Table 2. Affinity and definitions of year 3 learner focus groups.

\begin{tabular}{|c|c|}
\hline Affinity & Definition \\
\hline Art Style, AS & $\begin{array}{l}\text { The design art style of scene, background, } \\
\text { character, user interface }\end{array}$ \\
\hline Software Technology, ST & $\begin{array}{l}\text { Software operation, program understanding, } \\
\text { editing or editing settings }\end{array}$ \\
\hline Project Plan, PP & $\begin{array}{l}\text { Augmented Reality-related project design, } \\
\text { execution, and management capabilities }\end{array}$ \\
\hline Animation Technology, AT & $\begin{array}{l}\text { Dynamic editing capabilities of animation } \\
\text { making and films making }\end{array}$ \\
\hline Space Concept, SC & $\begin{array}{l}\text { 3D structural concept and understanding } \\
\text { ability of virtual reality space }\end{array}$ \\
\hline Film Effect, FE & $\begin{array}{l}\text { Design and editing capabilities of video } \\
\text { sound effects and background music }\end{array}$ \\
\hline Hardware Concept, HC & $\begin{array}{l}\text { Planning and design capabilities of interactive } \\
\text { device setup and environmental field }\end{array}$ \\
\hline Output Concept, OC & $\begin{array}{l}\text { Conceptual capabilities of various types of platform } \\
\text { compatibility settings and output format settings }\end{array}$ \\
\hline Interactive Design, ID & $\begin{array}{l}\text { Conceptual capabilities of interactive identification } \\
\text { graphics of Augmented Reality, object design }\end{array}$ \\
\hline
\end{tabular}

Table 3. Affinity analysis table, total frequency 153.

\begin{tabular}{|c|c|c|c|c|c|c|}
\hline No & Affinity & $\begin{array}{c}\text { Frequency } \\
\text { Order } \\
\text { (Descending) }\end{array}$ & $\begin{array}{c}\text { Frequency } \\
\text { Accumulation }\end{array}$ & $\begin{array}{c}\text { Cumulative } \\
\text { Percentage } \\
\text { (Relationship) }\end{array}$ & $\begin{array}{l}\text { Cumulative } \\
\text { Percentage } \\
\text { (Frequency) }\end{array}$ & Influence \\
\hline 1 & $\mathrm{AS} \rightarrow \mathrm{FE}$ & 6 & 6 & 1.4 & 3.9 & 2.5 \\
\hline 2 & $\mathrm{ST} \rightarrow \mathrm{AT}$ & 6 & 12 & 2.8 & 7.8 & 5.1 \\
\hline 3 & $\mathrm{ST} \rightarrow \mathrm{FE}$ & 6 & 18 & 4.2 & 11.8 & 7.6 \\
\hline 4 & $\mathrm{ST} \rightarrow \mathrm{OC}$ & 6 & 24 & 5.6 & 15.7 & 10.1 \\
\hline 22 & $\mathrm{AS} \rightarrow \mathrm{OC}$ & 4 & 121 & 30.6 & 79.1 & 48.5 \\
\hline 23 & $\mathrm{AS} \leftarrow \mathrm{ID}$ & 4 & 125 & 31.9 & 81.7 & 49.8 \\
\hline 24 & $\mathrm{AS} \leftarrow \mathrm{PP}$ & 3 & 128 & 33.3 & 83.7 & 50.3 \\
\hline 25 & $\mathrm{AS} \rightarrow \mathrm{ST}$ & 2 & 130 & 34.7 & 85.0 & 50.2 \\
\hline \multicolumn{7}{|c|}{$\ldots$} \\
\hline 70 & $\mathrm{HC} \rightarrow \mathrm{OC}$ & 0 & 153 & 97.2 & 100.0 & 2.8 \\
\hline 71 & $\mathrm{HC} \leftarrow \mathrm{ID}$ & 0 & 153 & 98.6 & 100.0 & 1.4 \\
\hline 72 & $\mathrm{OC} \rightarrow \mathrm{ID}$ & 0 & 153 & 100.0 & 100.0 & 0.0 \\
\hline
\end{tabular}

reached to the top with a value of $50.3 \%$ (shown as Figure 2(a)) and its cumulative percentage agreement is $83.7 \%$ (shown as Figure 2(b)). Meanwhile, the frequency is 3 , so only the relationship of frequency $\geq 3$ is taken into Interrelationship Drawing (IRD). 


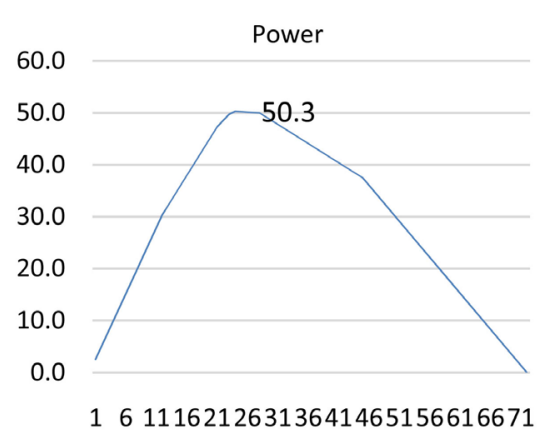

(a)

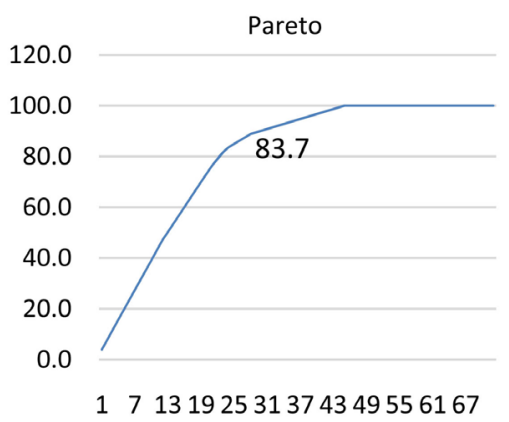

(b)

Figure 2. (a) Influence trends 50.3\%; (b) Cumulative percentage trend chart $83.7 \%$.

1 - 24 correlations are collated within IRD table and have out, in, and $\Delta$ quantity calculated. The results are shown (shown as Table 4): Project Plan (PP), Art Style (AS), Animation Technique (AT), Hardware Concept (HC) is the primary driver, Software Technique (ST), Final Effects (FE), and Interactive Design (ID) are secondary driver, Spatial Concept (SC) and Output Concept (OC) are a secondary outcome.

\subsubsection{Mind Map}

In interactive learning, planning in advance is a very important concept. From Figure 3 Mind Map, it is found that Project Plan is the most important factor in learning Augmented Reality, and Output Concept is the final result of Augmented Reality learning. The conceptual technique of Hardware and Software can affect Style and Design, and indirectly affect Animation Technique and 3D spatial Concept. The first layer consists learning from Hardware Concepts to the training and practice of Software Technique, and can be regarded as the conceptual basis before the second level of learning. Software Technique affect the second-level Final Effects and further affect Interactive Design, while Art Style influences Final Effects and Interactive Design. Therefore, the second layer of Art Style determines the Final Effects and Interactive Design of the screen. The third layer of Animation Technique to Spatial Concept also contains Final Effects and Interactive Design factors, fully confronting with the characteristics of Augmented Reality, the dynamic interaction of the real scene integrated with virtuality has actually reflected Augmented Reality learners' minds.

\subsection{In-Depth Onterview Data Analysis}

Nine affinities and twenty-two sub-affinities are generated by the focus group participants which in-depth participants being interviewed were asked to read first. The interviewee was asked to state their thoughts and opinions, and to be recorded and collected as data. Then, each respondent was asked to complete an ART form to list the relationship between the nine affiliations and explain the reasons. The ART data of the 3 seniors of the respondents were theoretically coded and the results showed that among 72 kinds of correlations, 108 results 

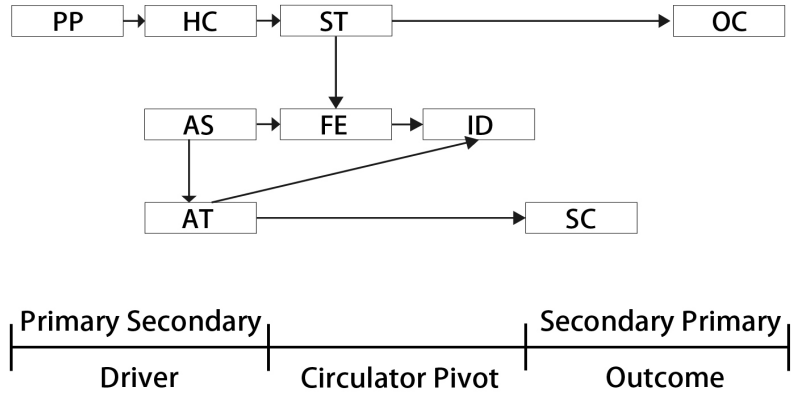

Figure 3. Focus group mind map.

Table 4. Interrelation table, focus group.

\begin{tabular}{ccccccccccccc}
\hline & AS & ST & PP & AT & SC & FE & HC & OC & ID & OUT & IN & $\Delta$ \\
\hline PP & $\uparrow$ & $\uparrow$ & & & & $\uparrow$ & $\uparrow$ & $\uparrow$ & $\uparrow$ & 6 & 0 & 6 \\
AS & & & $\leftarrow$ & $\uparrow$ & & $\uparrow$ & & $\uparrow$ & $\leftarrow$ & 3 & 2 & 1 \\
AT & $\leftarrow$ & $\leftarrow$ & & & $\uparrow$ & & & $\uparrow$ & $\uparrow$ & 3 & 2 & 1 \\
HC & & $\uparrow$ & $\leftarrow$ & & $\uparrow$ & & & $\leftarrow$ & $\uparrow$ & 3 & 2 & 1 \\
ST & & & $\leftarrow$ & $\uparrow$ & & $\uparrow$ & $\leftarrow$ & $\uparrow$ & $\leftarrow$ & 3 & 3 & 0 \\
FE & $\leftarrow$ & $\leftarrow$ & $\leftarrow$ & & & & & $\uparrow$ & $\uparrow$ & 2 & 3 & -1 \\
ID & $\uparrow$ & $\uparrow$ & $\leftarrow$ & $\leftarrow$ & & $\leftarrow$ & $\leftarrow$ & $\uparrow$ & & 3 & 4 & -1 \\
SC & & & & $\leftarrow$ & & & $\leftarrow$ & & & 0 & 2 & -2 \\
OC & $\leftarrow$ & $\leftarrow$ & $\leftarrow$ & $\leftarrow$ & $\leftarrow$ & $\uparrow$ & & $\leftarrow$ & 1 & 6 & -5 \\
\hline
\end{tabular}

were obtained. And, according to Pareto and explanatory power analysis (MinMax criteria), in 36th one (Spatial Concept $\rightarrow$ Interactive Design), Explanatory Power had reached to the top with a value of 36.1 (shown as Figure $4(\mathrm{a})$ ) and its cumulative percentage agreement had reached to $86.1 \%$ (shown as Figure 4(b)). Table 5 is the interrelationship table (IRD) of the interview participants, and Mind Map (SID) was finally collected and shown in Figure 5.

The results indicates that nine Affinity had one Affinity Project (PP) as the main driver, and three secondary drivers were: Art Style (AS), Animation Technique (AT), and Hardware Concept (HC), and three affinity cycles were : Software Technique (ST), Final Effects (FE), and Interaction Design (ID). The secondary output is the Spatial Concept (SC). The main output is the Output Concept (OC). From the Mind Map in Figure 5, we can see that Final Effects are the axis of circulation. It can be seen that regardless of the Technique, design, or conceptual style, the visual effects of Final Effects occupy a certain amount of weight in the learner's potential mind, and the Artistic Style influences the software and animation. Skills, formal attributes drive the development of technological change, and then realize the potential mental impression that the Hardware Concept has actual implementation of Interactive Design. 


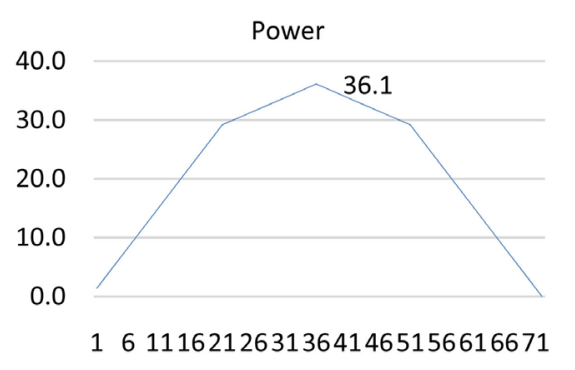

(a)

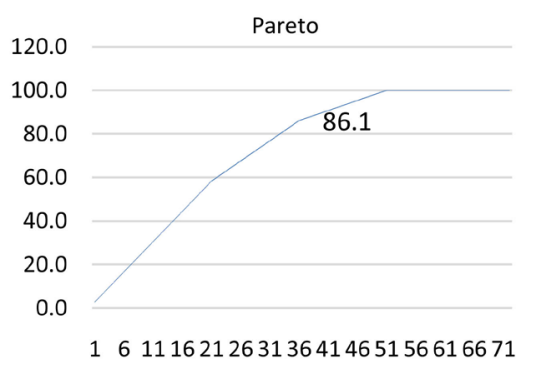

(b)

Figure 4. (a) Impact trends 36.1\%; (b) Cumulative percentage trend chart $86.1 \%$.

Depth Interviews
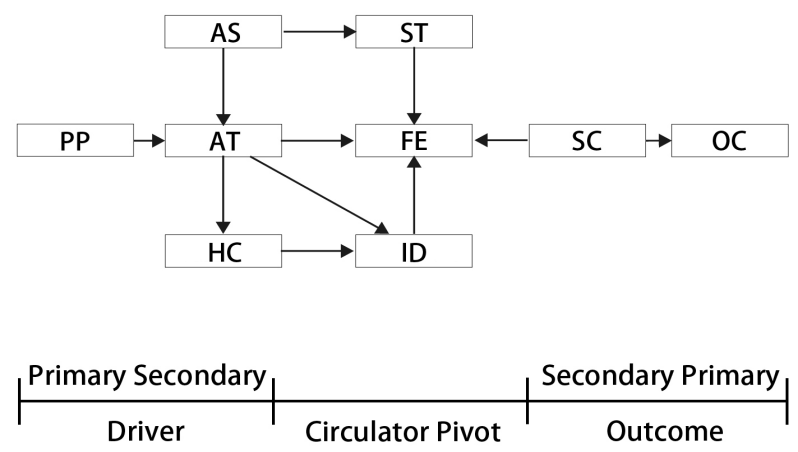

Figure 5. Depth interview mind map.

Table 5. Relationship table.

\begin{tabular}{lcccccccccccc}
\hline & AS & ST & PP & AT & SC & FE & HC & OC & ID & OUT & IN & $\Delta$ \\
\hline PP & $\leftarrow$ & $\uparrow$ & & $\uparrow$ & $\uparrow$ & $\uparrow$ & $\uparrow$ & $\uparrow$ & $\uparrow$ & 6 & 0 & 6 \\
AS & & $\uparrow$ & $\uparrow$ & $\uparrow$ & $\leftarrow$ & $\uparrow$ & $\uparrow$ & $\uparrow$ & $\uparrow$ & 3 & 2 & 1 \\
AT & $\leftarrow$ & $\leftarrow$ & $\leftarrow$ & & $\uparrow$ & $\uparrow$ & $\uparrow$ & $\uparrow$ & $\uparrow$ & 3 & 2 & 1 \\
$\mathrm{HC}$ & $\leftarrow$ & $\uparrow$ & $\leftarrow$ & $\leftarrow$ & $\uparrow$ & $\leftarrow$ & & $\leftarrow$ & $\uparrow$ & 3 & 2 & 1 \\
$\mathrm{ST}$ & $\leftarrow$ & & $\leftarrow$ & $\uparrow$ & $\leftarrow$ & $\uparrow$ & $\leftarrow$ & $\uparrow$ & $\leftarrow$ & 3 & 3 & 0 \\
$\mathrm{FE}$ & $\leftarrow$ & $\leftarrow$ & $\leftarrow$ & $\leftarrow$ & $\leftarrow$ & & $\uparrow$ & $\uparrow$ & $\leftarrow$ & 2 & 3 & -1 \\
$\mathrm{ID}$ & $\leftarrow$ & $\uparrow$ & $\leftarrow$ & $\leftarrow$ & $\leftarrow$ & $\uparrow$ & $\leftarrow$ & $\uparrow$ & & 3 & 4 & -1 \\
$\mathrm{SC}$ & $\uparrow$ & $\uparrow$ & $\leftarrow$ & $\leftarrow$ & & $\uparrow$ & $\leftarrow$ & $\uparrow$ & $\uparrow$ & 0 & 2 & -2 \\
$\mathrm{OC}$ & $\leftarrow$ & $\leftarrow$ & $\leftarrow$ & $\leftarrow$ & $\leftarrow$ & $\leftarrow$ & $\uparrow$ & & $\leftarrow$ & 1 & 6 & -5 \\
\hline
\end{tabular}

With the concept of project, one's mentality of ideas has become more mature, can also face the test of reality, but the initial and final mind is unanimously identified, and the $3 \mathrm{D}$ thinking of Spatial Concept is a very important conceptual factor of Augment Reality.

\subsection{Discussion}

\subsubsection{Verification of Focus Groups and Interviews}

Augmented Reality learners got nine affinities in the focus group. Through 
in-depth interview results, it was analyzed that the driver and output of the two groups are consistent, namely the Project Plan (PP) and Output Concept (OC). The middle of the cycle of the main shaft is also almost the same, but there is a way out of the logical sequence of output, can understand the thinking and production process of juniors and seniors graduates are different, but the output is unchanged. This shows that the final result of Interaction Design like Augmented Reality is the most important.

\subsubsection{Art Style Led Learning}

In the Technique of Augmented Reality learning, there are many related games engines and plug-in software that are constantly updated, and it has become easier to create related digital content. Therefore, the art design style has become an important indicator of content presentation. In the focus group Mind Map, Art Style (AS) influences Final Effects (FE) and Interactive Design (ID), and meanwhile drives Animation Technique (AT) learning, which is a relatively linear single learning in learning mode and shown as Figure 6. The seniors are also driven by Art Style in their mind performance. They further understand the interrelationships between the individual affinity studies and a reciprocal learning mode is formed and shown as Figure 7.

\subsubsection{Technical Capabilities of AV Final Effects}

The technical capabilities of Final Effects are the mind linear learning process of the focus groups of juniors; Mind Map of senior graduates is the core technology of circular concentration and the main learning parts in multimedia technology. Final Effects play a pivotal role in interactive design-based media and are an important factor in attracting the public. Therefore, it shows that more important mental ideas are formed among seniors.

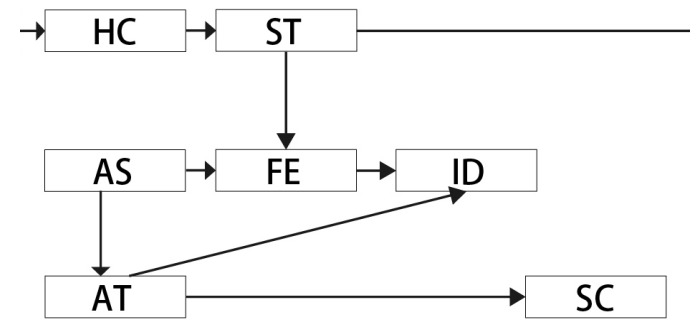

Figure 6. Focus group-linear single learning.

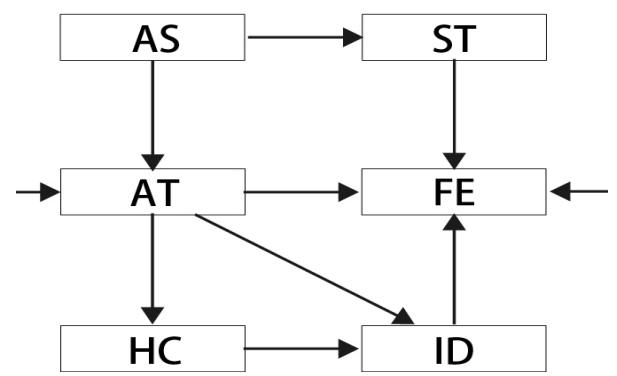

Figure 7. Depth interview-reciprocal learning mode. 
4.3.4. Animation Technique Influences the Concept of Interactive Design Interactive design is more flexible in concept and is the axis of the learning cycle of the Mind Map. The purpose of each technical skill is to learn interactive design. The Mind Map presented in the focus groups or senior interviews can be understood. As shown in Figure 8 and Figure 9, the affinity of Animation Technique (AT), the concept learning of dynamic image presentation may usually affect the presentation and learning of interactive design. It is very important in conceptual concepts. Animation Effect is almost an essential element in interactive design (Designing Big Tongue Blog, 2015) is also the core mentality of Augmented Reality learners.

\section{Findings of the Research}

The study relates to understand how human solve problems and an inferential process by applying Mind Map. By applying IQA methods and rigorous and systematic interactive analysis methods, the complex and intangible concepts are dealt through a series of systematic coding whose data can reflect the learners' potential ideas and further build a visual learner's Mind Map system. The cross-validation of the qualitative research of focus groups and in-depth interviews has provided a more integrated date analysis. Finally, we sum up the Augmented Reality learners' common Mental Model to provide reference value for digital media design teaching. And the generated propositions of Affinity related to each other can also be used as relevant planning and research about future digital media design courses. The conclusion is stated as below.

\subsection{The Learner's Mid Mode Has Generated Nine Affinities.}

They are Project Plan (PP), Art Style (AS), Animation Technique (AT), Hardware Concept (HC), Software Technique (ST), and Final Effects (FE), Interactive Design (ID), Spatial Concept (SC), and Output Concept (OC). The analysis in two stages considers the project plan as a main driver. The concept of output is the concept of generating, and generates a cycling of learning.

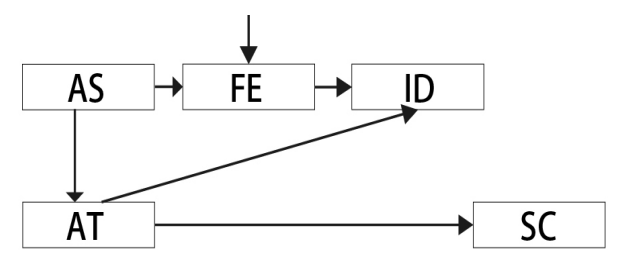

Figure 8. Focus group-interactive design is the axis of the learning cycle.

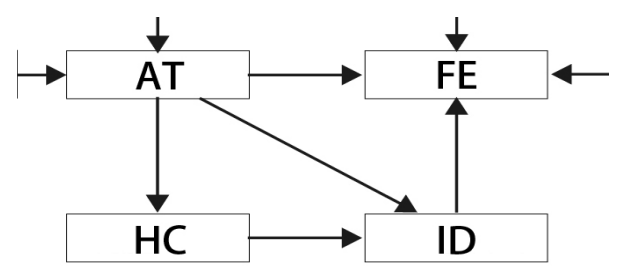

Figure 9. Depth interview-interactive design is the axis of the learning cycle. 


\subsection{The Concept of the Project Plan}

Only having integrated and detailed planning in advance one can accurately grasp the next required project and control schedule to be implemented and can confirm if the goal of each stage is achieved, and finally complete and review, discuss, and make amendments to generate complete results. Mind thinking is considered as a very important factor for learners and shall affect the follow-up development. In teaching practice, it also has the same concept. When you make a topic, students must have a complete plan idea beforehand and be able to make an overall plan step by step and implement, make and complet the project plan in object to individual topics and the required skills and Technique when learning.

\subsection{The Concept of Multimedia Design Skills}

Now thanks to the advancement of information technology, many ideas can be realized almost in all concepts. Learning all kinds of multimedia software and game engine has become easier and easier, even the packaged canned applications. One can only press a key to accomplish complex effects. However, the basic concept of the professional must be solid and step-by-step training to make such kinds of project in basic profession with Augment Reality jus like the mind development of the study: Software Technique, Animation Technique, Final Effects, Hardware Concepts, core design of Interactive Design are all basic concepts needed for multimedia design. Art Style is a key factor in such kind of multimedia content of Augmenting Reality in visual presentation. The mind development of learners also falls at the pivot location of driving follow-up learning.

\subsection{The Concept of Output Release}

Any design eventually generates finished products or products, the output release concept of digital media design output is the last output factor in learner's mind. The concept factor generated from the circular axis has different results from the learners of the two stages. It is the final result of learning that allows the users to use the finished product designed themselves. Therefore, the concept of applications (APP) on racks and learning and understanding various kinds of published platforms such as Google Play and APP Store are the learning scope of the output publishing concept.

\section{Conclusion}

Digital media design plays an important key role in all fields. The resources in all walks of life and various departments are integrated with the current trend nowadays in the world. Digital Media Design Department emphasizes creativity and visual aesthetics in training, and hopes that students can produce works with final effects. However, they usually lack concept in more commercialized and marketing packages. That is, they need to enhance the creative thinking 
methods of project plans. Jerry Hirshberg (2016) once said, "Creativity does not mean to break away from disciplined thinking (innovation and creativity), but to skip the deadlock through disciplined thinking. In accommodation with the rapid changes in modern society and the new concept of creators' entrepreneurship in the Internet of Things (IoT), we should fully use the cloud technology management and creative marketing personnel to learn and understand the concept of IoT technology applied to the practice. Methods of getting rid of traditional methods can also upgrade and enhance competitiveness. The study has discussed minds of Augmented Reality learners and further understood the courses of Media Design, Interactive Virtual Design, and Creative Design Marketing of Digital Media Design Department, to teach students how to use digital design technique to be applied into practice. The scope of digital media design is vast and complicated. Therefore, it is very important to learn related concepts and we must be able to cooperate in the way of professional division of labor of a team to establish a world of IoT to mutual help and share and cooperate.

\section{Conflicts of Interest}

The authors declare no conflicts of interest regarding the publication of this paper.

\section{References}

Chen, T. Y. (2008). The Digital Collection of "AR Augmented Reality Display Application". http://content.teldap.tw/index/blog/?p=758

Chris Griffiths. (2013). Ultra-Efficient Creative Thinking and Mind Map, Published by Shang Zhou, 136.

Designing Big Tongue Blog. (2015). Will Animation Be the Trend of Interface Design? https://designtongue.me/2015-

He, S.-X., \& Song, T.-Z. (2014). Review of Service Design Academic Research Development. Journal of Design, 19, 45-66. (In Chinese)

Jerry Hirshberg. (2016). The Creative Priority. https://www.harpercollins.ca/9780887309601/the-creative-priority/

Lien, Y.-M. (2010). Creativity in Mind 6+1. Published by Shang Zhou.

Northcutt, N., \& McCoy, D. (2004). Interactive Qualitative Analysis: A Systems Method for Qualitative Research. Thousand Oaks, CA: Sage.

YaHsun (2013). Three Points, Five Mind Concepts, Total Understanding What "Design Thinking" is! http://rebuzz.tw/2013/09/what-is-design-thinking.html

ZiKmund, Cooper, \& Schindler. (2010). What a Difference a Sample Makes. http://academyofwinebusiness.com/wp-content/uploads/2010/05/WhatADifference.pd $\underline{f}$ 